\title{
Evaluation of Intraoperative Imprint Cytology in Ovarian Tumors
}

Mahmoud Melies ${ }^{1}$, Abdelfattah Agamia ${ }^{1}$, Dina Mohamed Abdallah ${ }^{\star 2}$, Helmy Abelsattar Rady ${ }^{3}$, Amany Selim $^{4}$

${ }^{1}$ Obstetrics and Gynecology, Alexandria Faculty of Medicine, Egypt

${ }^{2}$ Pathology Department, Alexandria Faculty of Medicine, Egypt

${ }^{3}$ Obstetrics and Gynecology, Alexandria Faculty of Medicine, Egypt

${ }^{4}$ Obstetrics and Gynecology Department, Alexandria Faculty of Medicine, Egypt

*Corresponding author: Dina Mohamed Abdallah, Pathology Department, Alexandria Faculty of Medicine, Egypt, Tel: 01005676635; E-mail: dinabdalla@yahoo.com Received date: November 01, 2018; Accepted date: November 16, 2018; Published date: November 22, 2018

Copyright: (c) 2018 Melies M, et al. This is an open-access article distributed under the terms of the Creative Commons Attribution License, which permits unrestricted use, distribution, and reproduction in any medium, provided the original author and source are credited.

\begin{abstract}
Imprint cytology has been widely used in intraoperative diagnosis of various tumors. But its use in intraoperative diagnosis of ovarian neoplasms has not been widely recognized. There are only a few reports describing its accuracy and validity. We undertook this study to evaluate the accuracy of imprint cytology in the diagnosis of ovarian neoplasms and correlate it with histopathological diagnosis, taking it to be the gold standard. The present study was on 100 patients undergoing surgery for ovarian masses. For every ovarian mass imprint cytology was done and then compared to the final histopathologic diagnosis.
\end{abstract}

Imprint cytology in benign cases showed that $81.8 \%$ patients were negative and $18.2 \%$ patients were positive while in border line all cases were positive and in malignant group $11.9 \%$ patients were negative and $88.1 \%$ patients were positive. There was statistically significant difference between the studied groups where $P<0.001$. Imprint cytology was associated with the highest diagnostic accuracy $(84.88 \%)$ with sensitivity of $88.10 \%$ and specificity of $81.82 \%$ with a positive predictive value of $82.22 \%$ and a negative predictive value of $87.80 \%$.

Imprint cytology is a less expensive, simple, fast and reliable method for diagnosis of various ovarian neoplasms. The limitations we experienced in the study was insufficient cellularity in a few cases and interpretation errors especially in case of borderline epithelial tumors.

Diagnostic accuracy can be improved by extensive sampling in case of large ovarian tumors. Careful architectural assessment should be done. It is also recommended to correlate with clinical and radiological findings for better results. Imprint cytology does not alter the quality of biopsy specimen. Materials obtained from imprint can be used for flow cytometry and cytogenetic studies.

Keywords: Imprint cytology; Ovarian neoplasms; Intraoperative diagnosis; Biopsy specimen

\section{Introduction}

Ovarian cancer is the eighth most common cancer among women, and it includes about $4 \%$ of all women's cancers [1]. This disease has the highest morbidity and mortality rates among cancers of the reproductive system $[1,2]$. Lifetime risk of ovarian cancer in women is one in 71, and the chance of dying from the disease is 1 in 95 [3]. Ovarian cancer tends to occur among the most affluent women in the most highly industrialized countries [4].

The incidence of ovarian cancer is significant in Scandinavia, Israel (American-born or European-born residents), and North America. The frequency of ovarian cancer is low among East Indians and Africans, and African Americans and Latinos in the United States [4]. In Egypt, it is the fourth common cancer in women with crude incidence rate of 4.6/100,000. Its incidence peaks around 55-60 years of age reaching 24/100,000. Its incidence in Lower Egypt is 5.1/100,000 with higher incidence in Upper Egypt. An estimated 2.434 new cases of ovarian cancer were reported in Egypt every year [5].
A correct diagnosis helps in initiating the specific therapy in time, thus reducing morbidity and mortality. Histopathology is the universally accepted means of establishing a definitive pathological diagnosis, whereas use of cytology is controversial. Imprint is a very simple and rapid technique for tissue diagnosis. Imprint is a touch preparation in which tissue is touched on a slide and it leaves behind its imprint in the form of cells on the glass slide. We undertook this study to evaluate the accuracy of imprint cytology in the diagnosis ovarian neoplasms and correlate it with histopathological diagnosis, taking it to be the gold standard [6].

\section{Materials and Methods}

The present study was conducted in the Department of Gynaecologic oncology, El-Shatby Maternity University Hospital, during a time span of 14 months (February 2017 to March 2018) on 100 patients undergoing surgery for ovarian masses. Subjects have given their informed consent and the study protocol has been approved by the Alexandria faculty of medicine committee on human research.

For each case, clinical, laboratory and radiological data were collected. Grossly solid tumors/solid-cystic neoplasms were included 
Page 2 of 6

in the study. The excess of fluid i.e. blood, saline water, cyst contents, was gently blotted with dry gauze or filter paper to facilitate adhesions of the cells to the surface of glass. The tissue was touched on the glass slide at several points without undue pressure or lateral movements. Impressions were taken on clean labelled frosted slides. Smears thus prepared were fixed in $95 \%$ ethanol and stained rapidly with hematoxylin and eosin (H\&E). The slides were immediately dipped in hematoxylin for $1 \mathrm{~min}$, rinsed rapidly with distilled water, differentiated with ammonium hydroxide, counterstained with eosin by three slow dips, washed in tap water, dried, mounted on glass slides and covered with a coverslip. The time consumed for taking imprints, staining and reporting was 20 minutes [7].

The smears were evaluated for cellular morphology and architecture. The results were compared with final histopathology diagnosis keeping histopathology as gold standard. All benign lesions were reported as negative for malignancy. All borderline and malignant lesions were reported as positive for malignancy.

Monolayer and 2D cellular aggregate. Cells with uniform size and shape. Oval bland nuclei with regular chromatin and small, fine nucleoli, scant cytoplasm. Preservation of polarity and cohesiveness

Data was analyzed in the Statistical Package for Social Sciences (SPSS).

\section{Results}

This study included (100) patients with Ovarian mass diagnosed by clinical examination, ultrasonography, and/or radiological examination. Patients with risk malignancy index (RMI) more than 200. No history of chemotherapy or radiotherapy. No history of another pelvic malignancy.

The patient age in the study sample ranged from 18.0-77.0 years with a Mean \pm SD. $49.02 \pm 15.51$ and Median of 47 years old. With categorizing the age, data showed pooling in the (41-60) age category counting for $36 \%$ of study sample,32\% of patients their age $>60$ years, $30 \%$ in the (21-40) age category and $2 \%$ their age $\leq 20$ years. In the study group 56 patients were non-menopausal and 44 were menopausal. Menopausal duration ranged between 2-32 years with mean \pm S.D. $14.5 \pm 8.31$ years $($ Table 1$)$.

\begin{tabular}{|l|l|}
\hline & No. (\%) \\
\hline Age (years) & $49.0 \pm 15.5$ \\
\hline $0-20$ & $2(2 \%)$ \\
\hline $21-40$ & $30(30 \%)$ \\
\hline $41-60$ & $36(36 \%)$ \\
\hline $61-80$ & $32(32 \%)$ \\
\hline Menopausal status & \\
\hline Non-menopausal & $56(56 \%)$ \\
\hline Menopausal & $44(44 \%)$ \\
\hline
\end{tabular}

Table 1: Distribution of the studied cases according to demographic data $(n=100)$.

Imprint cytology in benign cases showed that $81.8 \%$ patients were negative and $18.2 \%$ patients were positive while in border line all cases were positive and in malignant group $11.9 \%$ patients were negative and $88.1 \%$ patients were positive. There was statistically significant difference between the studied groups where $\mathrm{P}<0.001$ (Table 2).

\begin{tabular}{|l|l|l|l|l|}
\hline \multirow{2}{*}{} & \multicolumn{2}{|l|}{ Final pathology } & \multirow{2}{*}{ P } \\
\cline { 1 - 4 } & $\begin{array}{l}\text { Benign } \\
(\mathbf{n = 4 4 )}\end{array}$ & $\begin{array}{l}\text { Border line } \\
(\mathbf{n = 1 4 )}\end{array}$ & $\begin{array}{l}\text { Malignant } \\
(\mathbf{n = 4 2 )}\end{array}$ & \\
\cline { 1 - 4 } Imprint cytology & & & & \\
\cline { 1 - 4 } Negative & $36(81.8 \%)$ & $0(0 \%)$ & $5(11.9 \%)$ & $<0.001$ \\
\hline Positive & $8(18.2 \%)$ & $14(100 \%)$ & $37(88.1 \%)$ & \\
\hline
\end{tabular}

Table 2: Relation between final pathology and cytology.

There were 14 cases diagnosed as border line by histopathology and were positive on imprint cytology.

Table 3, shows the agreement between final pathology and imprint cytology in total sample and it was associated with the highest diagnostic accuracy $(84.88 \%$ ) with sensitivity of $88.10 \%$ and specificity of $81.82 \%$ with a positive predictive value of $82.22 \%$ and a negative predictive value of $87.80 \%$.

\begin{tabular}{|l|l|l|}
\hline \multirow{2}{*}{} & \multicolumn{2}{|l|}{ Final pathology } \\
\cline { 2 - 3 } & Benign $(\mathbf{n}=\mathbf{4 4})$ & Malignant $(\mathbf{n}=\mathbf{4 2})$ \\
\hline Imprint cytology & & \\
\hline Negative & 36 & 5 \\
\hline Positive & 8 & 37 \\
\hline Sensitivity & 88.10 & \\
\hline Specificity & 81.82 & \\
\hline PPV & 82.22 & \\
\hline NPV & 87.80 \\
\hline Accuracy & 84.88 \\
\hline
\end{tabular}

Table 3: Agreement (sensitivity, specificity and accuracy) between final pathology and imprint cytology in total sample $(n=86)$.

Total number of cases studied was one hundred which were divided into epithelial tumors and non-epithelial tumors. All epithelial cases were further categorized into benign ( 25 cases), borderline (14 case) and malignant (31 cases). 

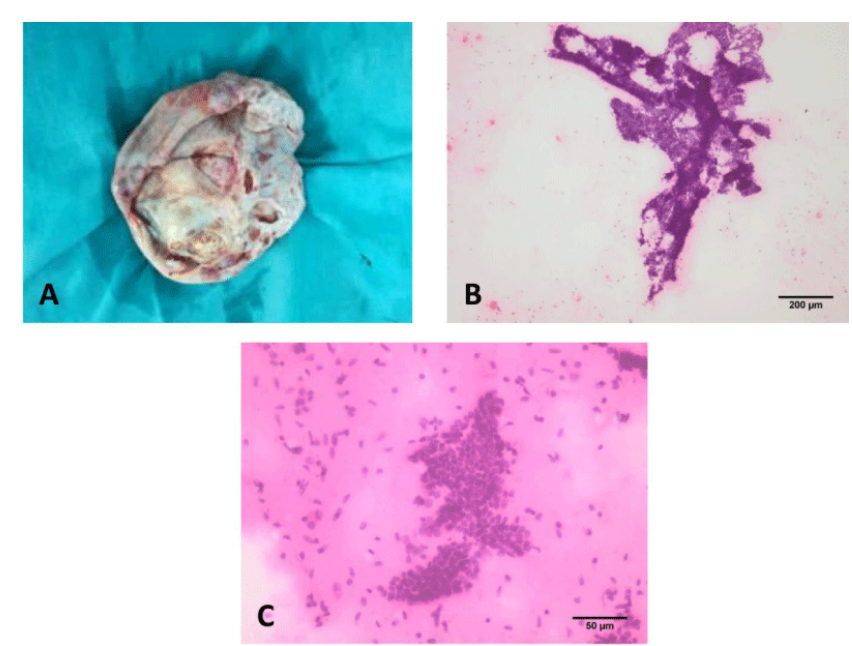

Figure 1: (a) Gross $4 \times 3 \mathrm{~cm}$, (b and c) Low and high power image of the imprint cytology of serous cystadenofibroma.

Patient's histological morphologic type with epithelial tumors shows that in benign epithelial tumors 15 patients had Serous cyst adenoma (their imprint cytology were negative) (Figure 1), 6 patients had Mucinous cyst adenoma (their imprint cytology were negative) and 4 patients had Benign Brenner tumors (their imprint cytology were positive) (Figure 2) while in border line epithelial tumors 10 patients were serous and 4 patients were mucinous (their imprint cytology were positive) and with malignant epithelial tumors 17 patients had Serous cyst adenocarcinoma (Figures 3-5) (13cases their imprint cytology were positive and 4 cases their imprint cytology were negative), 8 patients had Mucinous cyst adenocarcinoma (8 their imprint cytology were positive), 4 patients had endometrioid adenocarcinoma (their imprint cytology were positive) and 2 patients with clear cell carcinoma (their imprint cytology were positive).
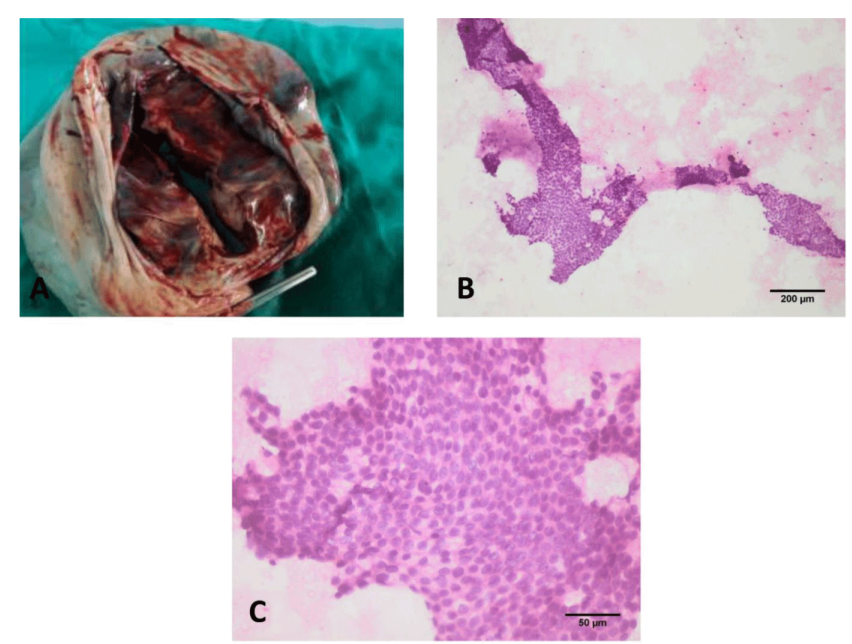

Figure 2: (a) gross $5 \times 5 \mathrm{~cm}$, (b and C) Low and high power view of suspicious montonous smear of Brenner tumor.
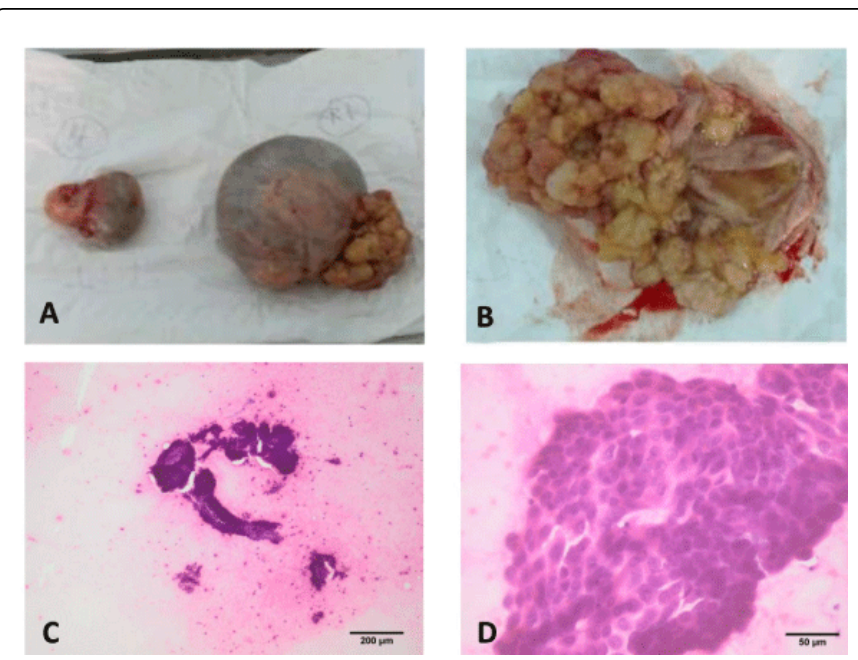

Figure 3: (a and b) gross $7 \times 4 \mathrm{~cm}$, $(\mathrm{c}$ and d) Low and high power view of imprint cytology of serous adenocarcinoma.

Regarding to non-epithelial cases were categorized into benign (19 cases) and malignant (11 cases). Morphologic type with non-epithelial tumors shows that in benign tumors 8 patients with mature cystic teratoma (Figure 6) (their imprint cytology were negative], 6 patients had fibrothecoma (4 cases their imprint cytology were negative and 2 cases their imprint cytology were positive), 4 patients had Fibroma (2 cases their imprint cytology were negative and 2 cases their imprint cytology were positive) and 1 patient was Sclerosing sex cord stromal tumors (their imprint cytology were negative) while with malignant tumors 8 patients with Granulosa cell tumors (their imprint cytology were positive), 1 patient had Immature teratoma (its imprint cytology was positive), 1 patient had Mixed malignant mullerian tumors (MMMT) (its imprint cytology was positive) and 1 patients with Sertoli-Ledig cell tumors (its imprint cytology was negative).

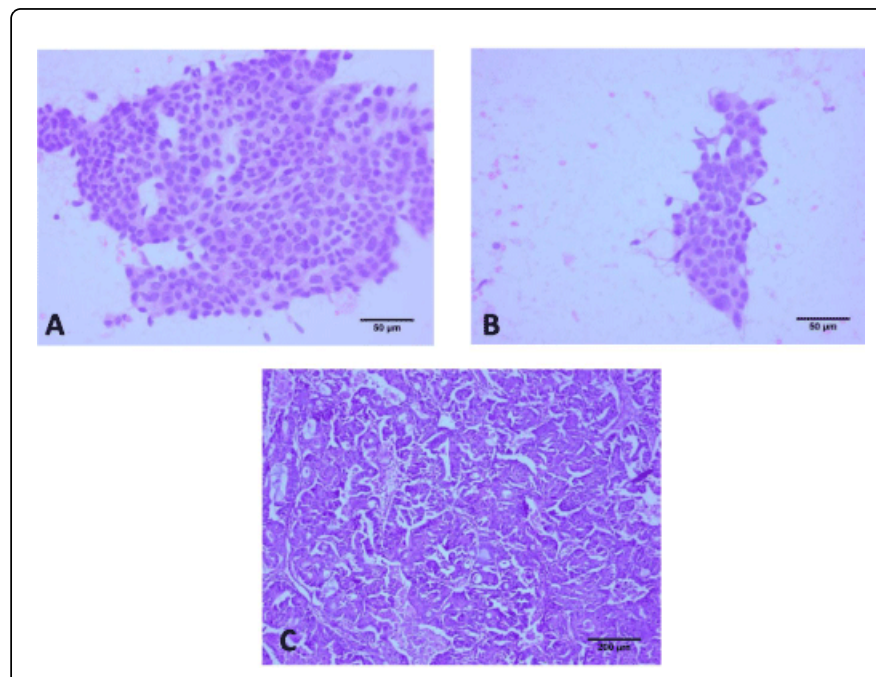

Figure 4: ( $a$ and b) imprint cytology and (c) histopathology of Serous cystadenocarcinoma. 
Citation: Melies M, Agamia A, Abdallah DM, Rady HA, Selim A (2018) Evaluation of Intraoperative Imprint Cytology in Ovarian Tumors. J Cytol

Page 4 of 6

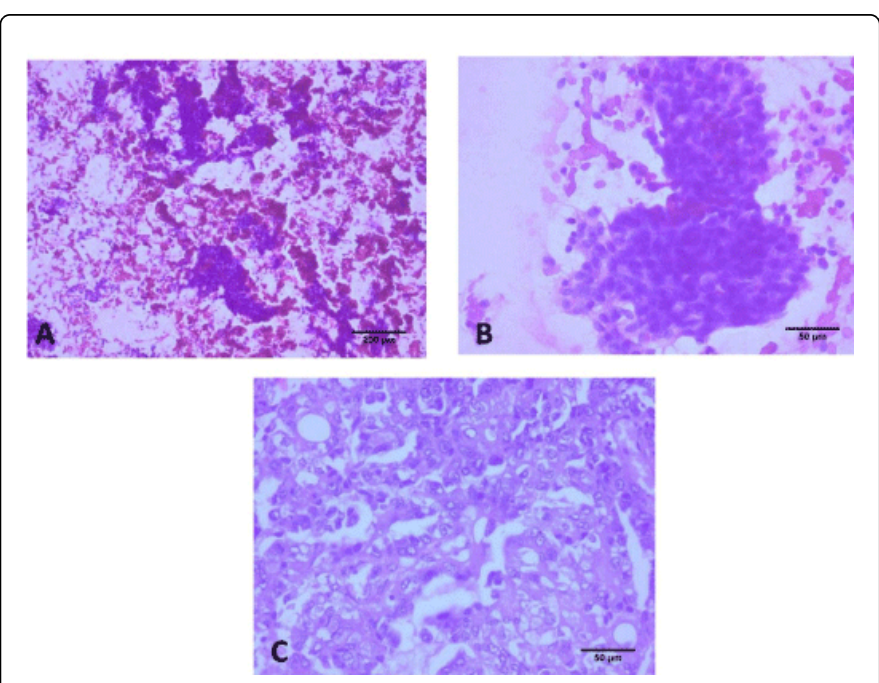

Figure 5: ( $\mathrm{a}$ and $\mathrm{b}$ ) low and high power of imprint cytology, (c) histopathology of High grade serous adenocarcinoma.
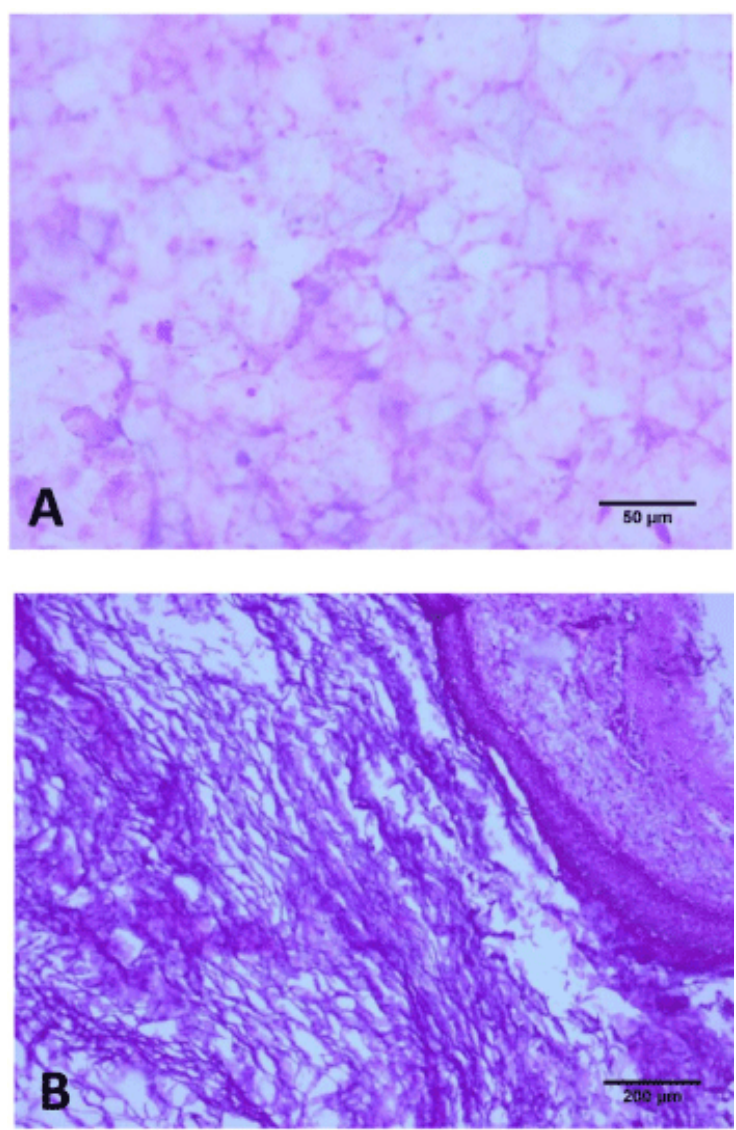

Figure 6: (a) Imprint and (b) histopathology of benign cystic mature teratoma.

\begin{tabular}{|c|c|c|c|}
\hline \multirow[t]{2}{*}{ Morphologic type } & \multirow{2}{*}{$\begin{array}{l}\text { Final } \\
\text { patholog } \\
\text { y }\end{array}$} & \multicolumn{2}{|c|}{ Imprint cytology } \\
\hline & & Negative & Positive \\
\hline \multicolumn{4}{|l|}{ Epithelial tumors } \\
\hline \multicolumn{4}{|l|}{ Benign } \\
\hline Serous cystadenoma & $15(15 \%)$ & $15(15 \%)$ & $0(0 \%)$ \\
\hline Mucinous cystadenoma & $6(6 \%)$ & $6(6 \%)$ & $0(0 \%)$ \\
\hline Benign Brenner tumors & $4(4 \%)$ & $0(0 \%)$ & $4(4 \%)$ \\
\hline \multicolumn{4}{|l|}{ Border line } \\
\hline Serous & $10(10 \%)$ & $0(0 \%)$ & $10(10 \%)$ \\
\hline Mucinous & $4(4 \%)$ & $0(0 \%)$ & $4(4 \%)$ \\
\hline \multicolumn{4}{|l|}{ Malignant } \\
\hline Serous cystadenocarcinoma & $17(17 \%)$ & $4(4 \%)$ & $13(13 \%)$ \\
\hline Mucinous cystadenocarcinoma & $8(8 \%)$ & $0(0 \%)$ & $8(8 \%)$ \\
\hline Endometrioid adenocarcinoma & $4(4 \%)$ & $0(0 \%)$ & $4(4 \%)$ \\
\hline Clear cell carcinoma & $2(2 \%)$ & $0(0 \%)$ & $2(2 \%)$ \\
\hline \multicolumn{4}{|l|}{ Non Epithelial tumors } \\
\hline \multicolumn{4}{|l|}{ Benign } \\
\hline Mature cystic teratoma & $8(8 \%)$ & $8(8 \%)$ & $0(0 \%)$ \\
\hline Fibrothecoma & $6(6 \%)$ & $4(4 \%)$ & $2(2 \%)$ \\
\hline Fibroma & $4(4 \%)$ & $2(2 \%)$ & $2(2 \%)$ \\
\hline Sclerosing sex cord stromal tumors & $1(1 \%)$ & $1(1 \%)$ & $0(0 \%)$ \\
\hline \multicolumn{4}{|l|}{ Malignant } \\
\hline Granulosa cell tumors & $8(8 \%)$ & $0(0 \%)$ & $8(8 \%)$ \\
\hline Immature teratoma & $1(1 \%)$ & $0(0 \%)$ & $1(1 \%)$ \\
\hline Mixed malignant mullerian tumors (MMMT) & $1(1 \%)$ & $0(0 \%)$ & $1(1 \%)$ \\
\hline Sertoli-Leydig cell tumors & $1(1 \%)$ & $1(1 \%)$ & $0(0 \%)$ \\
\hline
\end{tabular}

Table 4: Distribution of the studied cases according to morphologic type $(n=100)$.

\section{Discussion}

Intraoperative consultation is a very important aspect of surgical pathology that often guides the surgeon's hand. Traditionally, intraoperative pathological evaluation is based on frozen sections. In the areas of the world where access to intraoperative histological diagnosis is limited, imprint cytology is probably the only means of rapid intraoperative consultation $[8,9]$.

Imprint cytology has been widely used in intraoperative diagnosis of various tumors. But its use in intraoperative diagnosis of ovarian neoplasms has not been widely recognized. There are only a few reports describing its accuracy and validity $[10,11]$.

We have done intraoperative imprint cytological examination in 100 cases fulfilling the inclusion criteria and followed it up histologically. 
Page 5 of 6

Out of them $44 \%$ were benign tumors, $14 \%$ were border line and $42 \%$ were malignant.

Predominantly $42 \%$ of cases were of serous in nature and most cases were malignant. Verma and Bhatia [12] and Tushar et al. [13] etc., had also found similar results.

Serous cyst adenoma comprised 15 cases $(15 \%$ ) of all ovarian tumors. Similar incidence is quoted by Saxena, et al. [14], Verma and Bhatia [12] and Tyagi, et al. [15]. Age range was between 43 and 77 years, all of them were unilateral, cystic and contained clear fluid. Malignant serous tumors accounted for $27 \%$ of all ovarian tumors. Ramachandran, et al. [16] found a lower incidence of 7.09\%.

Imprint cytology was $92.75 \%$ accurate. In similar studies by Shahid, et al. and Higgins, et al., high diagnostic accuracy was seen in the case of serous adenocarcinoma $[17,18]$.

Epithelial borderline neoplasms are hard to differentiate from malignant neoplasms only on cytology due to similar cytological features [19], presence of complex branching architecture, hyperchromatic nuclei, and pleomorphism [20] as the only difference between them is stromal invasion [21]. Histopathology is essential to report presence or absence of stromal invasion. This is the limitation of the study also experienced by Nagai, et al. [20].

Mucinous tumors formed the second most common epithelial tumors of the ovary (18\% ). Pravakar and Maingi [22] reported them to be $25 \%$. They are the largest tumors among the ovarian tumors. The largest tumor seen in this study was of $13 \mathrm{~kg}$ which was a mucinous cyst adenoma. Tushar, et al. [13] also studied mucinous cyst adenocarcinoma in their study as the largest tumor.

Imprint cytology has shown $100 \%$ diagnostic accuracy in case of mucinous cyst adenoma and mucinous cyst adenocarcinoma. The smears were moderately cellular showing clusters of mucinous cells with high N/C ratio. Nuclei were pleomorphic and hyper-chromatic. A study by Tushar et al showed $100 \%$ correlation in mucinous tumors with clinical correlation [13].

All cases of benign Brenner tumors were diagnosed positive (suspicious monotonous dark cells) by imprint cytology. The smears were hypercellular showing poorly cohesive cells. The cells comprises of well-defined boundaries and eosinophilic cytoplasm. Nuclei were vesicular with prominent eosinophilic nucleoli. Background showed scattered lymphocytes. Statsny, et al. labeled it as tigeroid background [23].

The cytological features of Brenner tumor have been described as sheets of epithelial cells of benign appearance with ovoid nuclei with a 'coffee-bean' appearance, opportunities to observe the cytologic features of this condition are rare.

In the four endometrioid carcinomas two were misinterpreted as mucinous adenocarcinoma while the other two cases of endometrioid carcinoma were correctly diagnosed on imprint cytology. The hypocellular smears revealed cellular aggregates forming vague glandular configuration. The cells were columnar with pleomorphic hyper-chromatic nuclei. Khunamornpong, et al. reported difficulty in differentiating between Serous and Endometrioid carcinomas due to overlapping cytologic features $[20,24]$.

All (two) cases of clear cell carcinoma were correctly diagnosed by imprint cytology showing clear cells cuboidal in shape with mitotic figures.
All 8 cases of mature teratoma were identified correctly on imprint cytology. The hypocellular smears showed anucleated squames and keratin flakes. Background was inflammatory. Similar results were observed by Tushar et al. [13].

There were eight cases of granulosa cell tumor showing hypocellular aspirates. The cells were oval with vesicular nucleus. Nuclear grooving was identified that was helpful in making the correct diagnosis also for Shalinee, et al. in their study [25].

One case was Malignant Mixed Mullerian Tumor which was interpreted as poorly differentiated serous carcinoma.

One case Sertoli-Ledig cell tumor was misinterpreted as fibroma with oncocytic cells,vesicular nuclei and prominent nucleoli [26].

Six cases of fibrothecoma were labeled as four cases benign stromal tumors and two cases were positive. The moderately cellular smears showed bland spindle cells. The cells showed finely granular chromatin. The findings correlate with the study by Vijaykumar and Yang, and Mesia [27,28].

There are few studies regarding imprint cytology of ovarian neoplasm. In this study sensitivity was $84.85 \%$, specificity $100 \%$, diagnostic accuracy $92.75 \%$. In the study of imprint cytology of ovarian neoplasms done by Tushar, et al. [13], the sensitivity and specificity were $93 \%$ and $92 \%$ respectively. Nadji, et al. [29] had a sensitivity and specificity of $96.4 \%$ and $92 \%$ respectively in their study on cytology of ovarian neoplasms. The overall diagnostic accuracy of imprint cytology was satisfactory with $92 \%$ of cases correlating with histopathological diagnosis according to Shalinee, et al. with specificity of $96.4 \%$ and $92 \%$ respectively in their study [26]. Dey Soumit, et al. had sensitivity $96.2 \%$, specificity $75 \%$, and diagnostic accuracy $83.3 \%$ compared to our study. Mikami [30] studied sclerosing stromal tumor (SST) of ovary for imprint cytology. Considering SST most commonly occurs in young woman requiring conservative treatment, imprint cytology seems to have potential diagnostic significance.

The limitations we experienced in the study was insufficient cellularity in a few cases and interpretation errors especially in case of borderline epithelial tumors.

Diagnostic accuracy can be improved by extensive sampling in case of large ovarian tumors. Careful architectural assessment should be done. It is also recommended to correlate with clinical and radiological findings for better results.

Imprint cytology does not alter the quality of biopsy specimen [31]. Materials obtained from imprint can be used for flow cytometry and cytogenetic studies [20].

\section{Conclusions}

Imprint cytology is a less expensive, simple, fast and reliable method for diagnosis of various ovarian neoplasms.

This research was accepted by the ethics committee of Alexandria faculty of medicine.

\section{References}

1. Ferlay J (2010) Estimates of worldwide burden of cancer in 2008: GLOBOCAN 2008. International journal of cancer Int J Cancer 127: 2893-2917. 
2. Sankaranarayanan R, Ferlay J (2006) Worldwide burden of gynaecological cancer: the size of the problem Best Prac Res Clin Obstet Gynaecol 20: 207-225.

3. Ahlgren JD (1996) Epidemiology and risk factors in pancreatic cancer Semin Oncol 23: 241-250.

4. Coleman MP, Esteve J, Damiecki P (1993) Trends in Cancer Incidence and Mortality. Lyon, International Agency for Research on Cancer.

5. Ibrahim AS, Khaled HM, Mikhail NN, Baraka H, Kamel H (2014) Cancer incidence in Egypt: Results of the national population-based cancer registry program. J Cancer Epidemiol 2014: 1-18.

6. Loncar B, Pajtler M, MilicicJuhas V, Kotromanovic V, Staklenac B, et al (2007) Imprint cytology in laryngeal and pharyngeal tumours. Cytopathology 18: 40-43.

7. Rahman K, Siddiqui FA, Zaheer S, Sherwani MKA, Shahid M, et al. (2010) Intraoperative cytology-role in bone lesion. Diagn Cytopathol 38: 639-644.

8. Michael C, Lawrence W, Bedrossian C (1996) Intraoperative consultation in ovarian lesions: a comparison between cytology and frozen section. Diagn Cytopathol 15: 387-394.

9. Khalid A, Haque AU (2004) Touch impression cytology versus frozen section as intraoperative consultation diagnosis. Int J Pathology 2: 63-70.

10. Suen KC, Wood WS, Syed AA, Quenville NF, Clement PB (1978) Role of imprint cytology in intraoperative diagnosis, value and limitations. J Clin Path 31: 328-337.

11. Lee TK (1982) The value of imprint cytology in tumor diagnosis: A retrospective study of 527 cases in China. Acta Cytol 26: 169-171.

12. Verma K, Bhatia A (1982) Ovarian neoplasms - A study of 403 tumours. J Obstetric Gynecol India 3: 106-111.

13. Tushar K, Asaranti K, Mohapatra PC (2005) Intraoperative cytology of ovarian tumors. J Obstet Gynecol India 55: 345-349.

14. Saxena HMK, Devu G, Parkas P (1980) Ovarian neoplasms-A retrospective study of 356 cases. J Obstet Gynecol India 30: 522-527.

15. Tyagi SP, Tyagi GK, Logani KB (1967) A pathological study of 120 cases of ovarian tumours. J Obstet Gynecol India 17: 423-433.

16. Ramachandran G, Hiralal KR, Chhinnamma KK (1972) Ovarian neoplasm-A study of 903 cases. J Obstet Gynecol India 22: 309-315.

17. Shahid M, Zaheer S, Mubeen A, Rahman K, Sherwani R (2012) The role of intraoperative cytology in the diagnostic evaluation of ovarian neoplasms. Acta Cytologica 56: 467-473.
18. Higgins R, Matkins J, Marroum M (1999) Comparison of fine-needle aspiration cytologic findings of ovarian cysts with ovarian histologic findings. Am J Obstet Gynecol 180: 550-553.

19. Nagai Y, Tnanaka N, Horiuci F, Ohki S, Sekiya S (2001) Diagnostic accuracy of intraoperative cytology in ovarian epithelial tumour. Int J Gynaecol Obstet 72: 159-164.

20. Alvarez SC, Sica A, Melesi S, Feijó A, Garrido G, et al. (2011) Contribution of intraoperative cytology to the diagnosis of ovarian lesions. Acta Cytol 55: 85-91.

21. Khunamornpong S, Siriaunkgul S (2003) Scrape cytology of the ovaries: potential role in intraoperative consultation of ovarian lesions. Diagn Cytopathol 28: 250-257.

22. Pravakar BRE, Maingi K (1989) Ovarian tumours-prevalence in PunjabA study of 636 cases. Ind J Pathol Microbiol 32: 276-281.

23. Stastny J, Johnson D, Frable W (1992) Fine needle aspiration of nonneoplastic and neoplastic ovarian lesions. Acta Cytol 36: 611.

24. Roy M, Bhattacharya A, Roy A, Sanyal S, Sangal M, et al. (2003) Fine needle aspiration cytology of ovarian neoplasms. J Cytol 20: 31-35.

25. Rao S, Sadiya N, Joseph LD, Rajendiran S (2009) Role of scrape cytology in ovarian neoplasms. J Cytol 26: 26-29.

26. Nguyen GK, Redburn J (1992) Aspiration biopsy of granulosa cell tumor of the ovary: Cytologic findings and differential diagnosis. Diagn Cytopathol 8: 253-257.

27. Vijayakumar A (2013) The diagnostic utility of intraoperative cytology in the management of ovarian tumors. Journal of Clinical and Diagnsotic Research 7: 1047-1050.

28. Yang G, Mesia A (1999) FNAC of fibrothecoma of the ovary. Diagn Cytopathol 22: 284-286.

29. Nadji M, Greening SE, Sevin BU (1979) Fine needle aspiration cytology in gynaecologic oncology. ii. morphologic aspects. Acta Cytol 23: 380-388.

30. Mikami M (2003) Tumour imprint cytology sclerosing stromal tumour of ovary. Diagnostic Cytopath 28: 54-57.

31. Misra SP, Misra V, Dwivedi M, Singh P (1998) Diagnosing H.Pylori by imprint cytology: can the same biopsy specimen be used for histology? Diagn Cytopathol 18: 330-332. 